\title{
Quantitative X-Ray Microanalysis in the Analytical Electron Microscope
}

\author{
Raynald Gauvin
}

Department of Mining, Metals \& Materials Engineering, McGill University, 3610

University Street, Montréal, Québec, Canada, H3A 2B2

The foundations of quantitative x-ray microanalysis in the analytical electron microscope were published in the famous paper of Goldstein et al. [1]. The weight fraction of two elements $\mathrm{A}$ and $\mathrm{B}, \mathrm{C}_{\mathrm{A}}$ and $\mathrm{C}_{\mathrm{B}}$, are related to their net $\mathrm{x}$-ray intensities $\mathrm{I}_{\mathrm{A}}$ and $\mathrm{I}_{\mathrm{B}}$ by this equation:

$$
\frac{\mathrm{C}_{\mathrm{A}}}{\mathrm{C}_{\mathrm{B}}}=\mathrm{K}_{\mathrm{A}-\mathrm{B}} \frac{\mathrm{I}_{\mathrm{A}}}{\mathrm{I}_{\mathrm{B}}}
$$

where $K_{A-B}$ is the well known Cliff - Lorimer $K$ factor. Equation (1) is valid when absorption and fluorescence effects are negligible. $\mathrm{K}_{\mathrm{A}-\mathrm{B}}$ can be determined with the measurement of x-ray net intensities using a standard of known composition or it can be computed using an equation based from first principles that was derived by Goldstein et al. [1]. Because of uncertainties on fundamental parameters, especially the ionization cross-sections, experimental $\mathrm{K}_{\mathrm{A}-\mathrm{B}}$ factors are more accurate. Gauvin \& L'Espérance [2] have proposed to use the ratio of two experimental $\mathrm{K}_{\mathrm{A}-\mathrm{B}}$ factors obtained at 2 different accelerating voltages, $\mathrm{R}$, in order to determine the $\mathrm{C}_{\mathrm{nl}}$ parameter of the Bethe equation of the ionization cross sections then allowing computing the $\mathrm{K}_{\mathrm{A}-\mathrm{B}}$ factors, and saving time to perform quantitative $\mathrm{x}$-ray microanalysis. The great advantage of equation (1) is that $\mathrm{K}_{\mathrm{A}-\mathrm{B}}$ is independent of composition when x-rays are generated by primary electrons only, because they do not loose significant energy in the TEM. Therefore, a $\mathrm{K}_{\mathrm{A}-\mathrm{B}}$ factor determined at one composition can be used with another composition. However, $\mathrm{K}_{\mathrm{A}-\mathrm{B}}$ becomes dependant of composition when $\mathrm{x}$-rays are generated by fast secondary electrons (FSE) [3]. Figure [1] shows $\mathrm{K}^{*}$, the ratio of $\mathrm{K}_{\mathrm{A}-\mathrm{B}}$ computed with and without FSE for the B-N, B-Fe and B-Nd systems at $100 \mathrm{keV}$. Clearly, when A or B is a light element, the $\mathrm{K}_{\mathrm{A}-\mathrm{B}}$ factor can be very sensitive to composition and equation (1) is no longer valid. An experimental validation of these Monte Carlo simulations is therefore needed. The paper of Goldstein et al. [1] presented an equation to compute the beam broadening, $b$, of primary electrons in the TEM based on a single scattering model. Figure [2] shows $b$ (simulated and computed for a zero beam diameter) as a function of thickness for $\mathrm{Al}$ and $\mathrm{Fe}$ at $100 \mathrm{keV}$ with their model and by using Monte Carlo simulations. In the practical range of TEM thin foils $(20$ to $100 \mathrm{~nm})$, the single scattering model is valid. However, Monte Carlo simulations will have to be used to determine the ultimate resolution of microanalysis in the TEM.

\section{References}

1. J. I. Goldstein, J. L. Costley, G. W. Lorimer and S. J. B. Reed (1977), Scanning Electron Microscopy, Vol. I, pp. 315 - 324.

2. R. Gauvin \& G. L'Espérance (1991), J. of Microscopy, Vol. 163, Pt. 3, pp. 295-306.

3. R. Gauvin \& G. L'Espérance (1992), J. of Microscopy, Vol. 168, Pt. 2, pp. 153-167. 


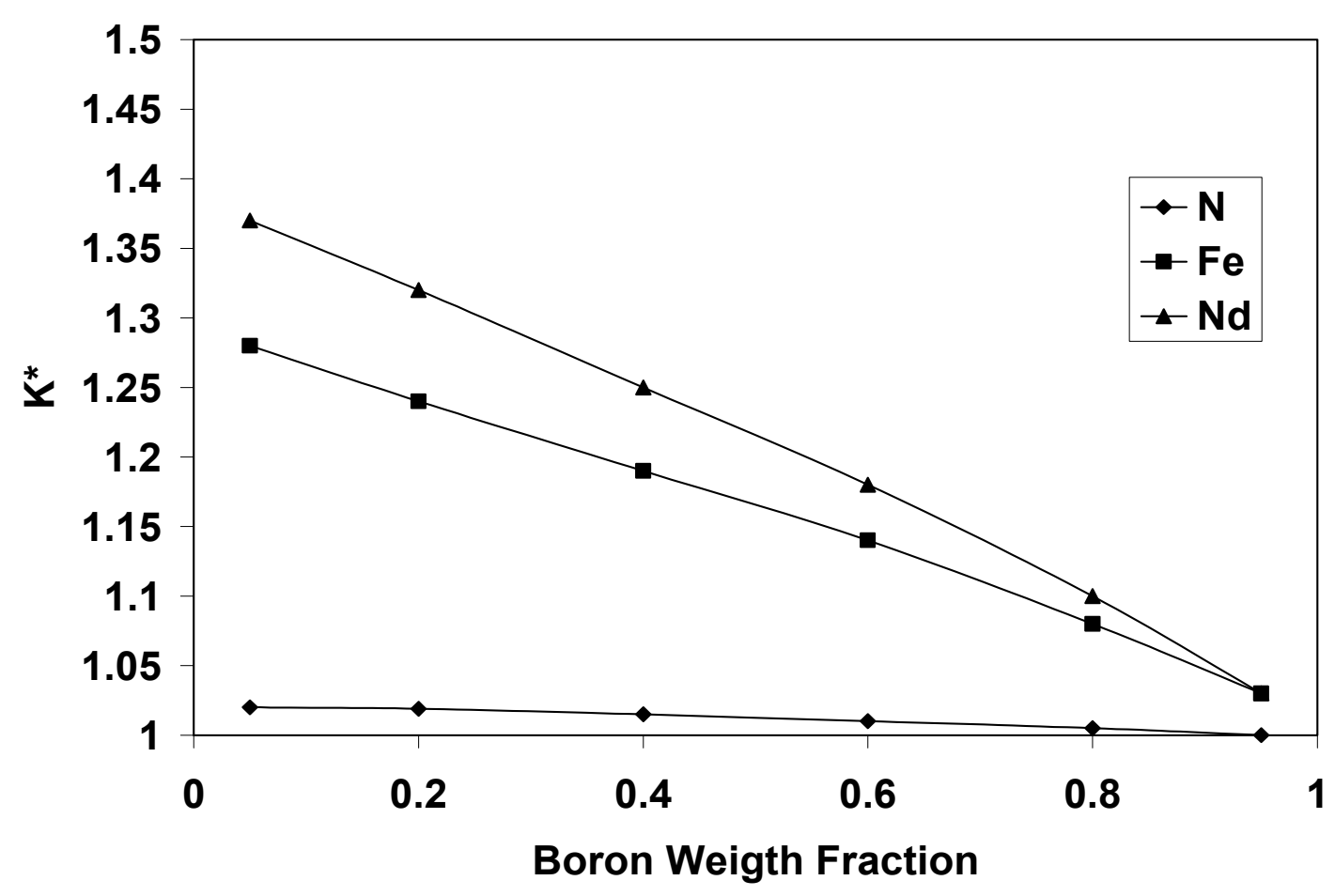

Figure [1] $K^{*} B-X$ versus $B$ composition at $100 \mathrm{keV}$ and $100 \mathrm{~nm}$ of thickness.

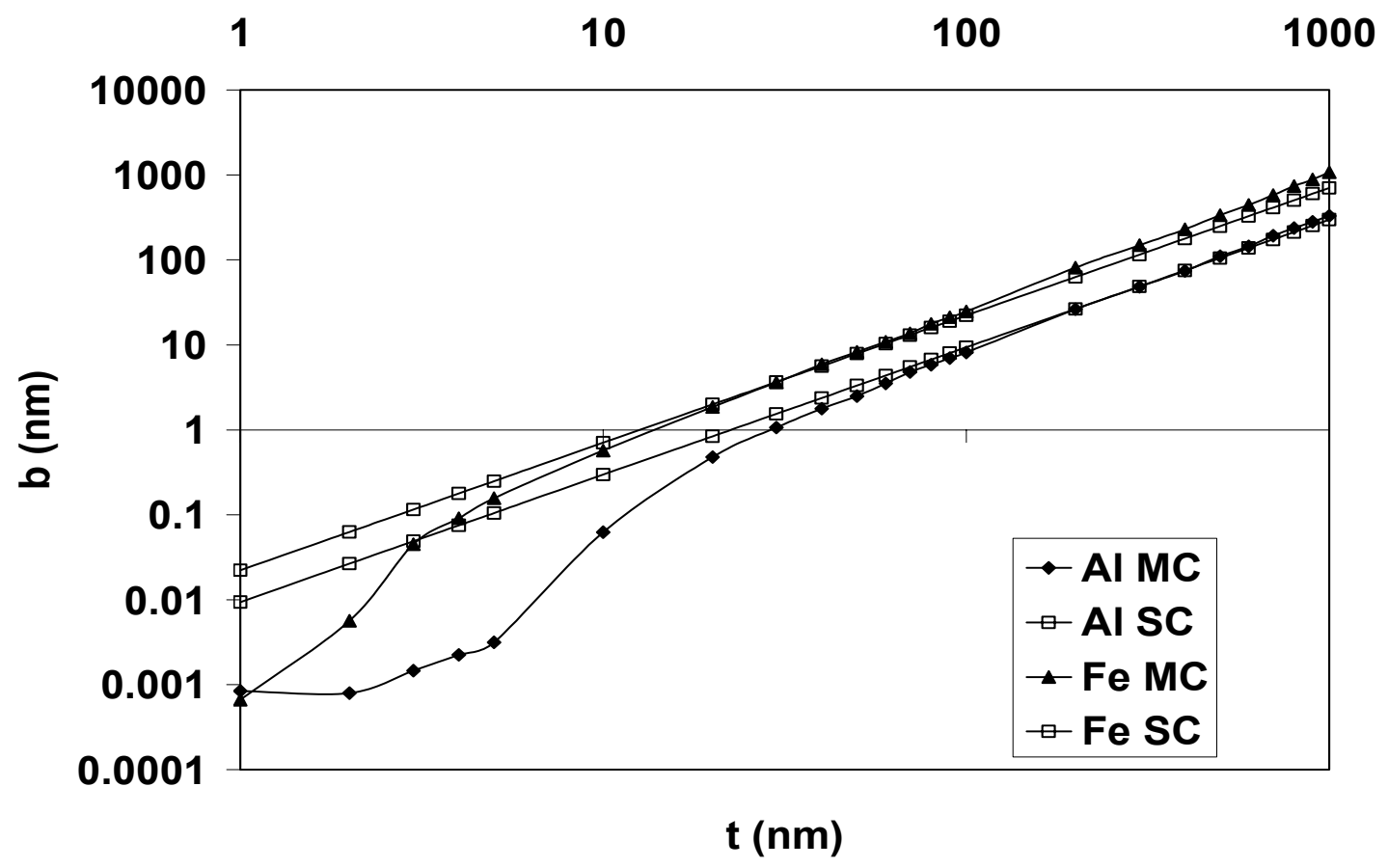

Figure [2] b versus t at $100 \mathrm{keV}$ from Monte Carlo (MC) and single scattering model (SC) of Goldstein et al.[1]. 